\title{
REDES FORMAIS E INFORMAIS ENTRE ESTUDANTES UNIVERSITÁRIOS: UMA ANÁLI- SE E COMPARAÇÃO DAS ESTRUTURAS GERAIS, SIMILARIDADES E DIFERENÇAS DAS REDES
}

\author{
FORMAL AND INFORMAL NETWORKS AMONG UNIVERSITY STUDENTS: AN ANALYSIS AND COM- \\ PARISON OF THE GENERAL STRUCTURES, SIMILARITIES AND DIFFERENCES OF THE NETWORKS
}

\author{
Taís Pasquotto Andreoli ${ }^{1}$ \\ ORCID: http://orcid.org/0000-0002-9173-9294
}

\section{Sandra Bergamini Leonardo 2}

ORCID: http://orcid.org/0000-0003-2815-387X

\author{
Milton Carlos Farina ${ }^{3}$ \\ ORCID: http://orcid.org/0000-0003-0551-8282
}

\author{
Ana Boteon de Lima ${ }^{4}$ \\ ORCID: http://orcid.org/0000-0003-1440-8843
}

1, 2, 3,4 (Universidade Municipal de Sao Caetano do Sul -USCS, São Caetano do Sul - SP, Brasil)

\section{RESUMO}

O trabalho teve como objetivo analisar e comparar as redes sociais de amizade pessoal (informal) e de colaboração profissional (formal) de duas turmas de alunos universitários dos cursos de Administração e Contabilidade, segundo suas percepções e de acordo com a importância do relacionamento que eles conferem a si mesmos. Para que isso fosse possível, o trabalho realizou uma revisão da literatura focada nas bases conceituais de redes sociais, redes formais e informais e na análise de redes sociais. O procedimento metodológico adotado foi uma pesquisa de estudo de campo, realizada por meio da análise de redes sociais, que tem foco estrutural, compreendendo tanto sua perspectiva macro quanto micro. Foram utilizadas as medidas de centralidade (de grau, intermediação e proximidade) e as medidas estruturais (densidade e reciprocidade). Com isso, foi possível compreender as estruturas gerais das redes das duas turmas analisadas, identificando as similaridades e diferenças em relação às medidas adotadas.

Palavras-chaves: Análise de redes sociais. Redes formais. Redes informais. Estudante universitário.

\section{ABSTRACT}

The purpose of this study was to analyze and compare social networks of personal (informal) friendship and professional (formal) collaboration of two classes of university students of Administration and Accounting courses, according to their perceptions and according to the importance of the relationship they confer to themselves. For this to be possible, the work carried out a review of the literature focused on the conceptual bases of social networks, formal and informal networks and the analysis of social networks. The methodological procedure adopted was a field study research, carried out through the analysis of social networks, which has a structural focus, including both macro and micro perspectives. The measures of centrality (degree, intermediation and proximity) and structural measures (density and reciprocity) were used. With this, it was possible to understand the general network structures of the two groups analyzed, identifying the similarities and differences in relation to the measures adopted.

Keywords: Analysis of social networks. Formal networks. Informal networks. University student. 


\section{INTRODUÇÃO}

O estudo da análise das redes sociais vem adquirindo crescente importância pela contribuição na compreensão da dinâmica das relações sociais, abordando tanto a estrutura geral das redes quanto os padrões de relacionamento existentes entre os atores sociais, com base nas suas medidas. De maneira resumida, pode-se entender uma rede social como um conjunto de nós e elos que os interligam, visualmente explicativos, que representam os atores e as relações que compartilham (BRANDES; KENIS; RAAB, 2005).

Nesse contexto, um conceito inerente às redes sociais se refere à formalidade ou informalidade de suas relações. De uma maneira geral, a rede social formal está relacionada às relações que foram estruturadas e prescritas previamente, enquanto que a rede social informal se refere às relações que surgem espontaneamente, por meio da ação voluntária dos próprios participantes (LEONARDO et al., 2019). Ainda que diversos estudos discorram sobre essa questão, tanto Soda e Zaheer (2012) quanto McEvily, Soda e Tortoriello (2014) argumentam que são poucos os trabalhos que se preocupam em comparar e avaliar a consistência entre as redes formal e informal existentes, carecendo de abordagens holísticas, que abarquem ambas as redes simultaneamente.

O estudo das redes sociais de forma abrangente se apresenta como ainda mais importante em ambientes que demandam interação e troca de informação, ideias e conhecimentos, como é o caso das instituições de ensino de nível superior (TEIXEIRA, 2011). Aliado a isso, trata-se de ambientes em que são demandados ambos os papéis de seus participantes, formal e informal, praticamente de maneira concomitante. Apesar disso, são ainda mais escassos os estudos voltados para o estudo das redes formal e informal entre estudantes universitários.

À luz do exposto, o trabalho teve como objetivo comparar as redes sociais de amizade pessoal (informal) e de colaboração profissional (formal) de alunos universitários, segundo suas percepções, comparando também as reciprocidades identificadas tanto na relação formal quanto informal às notas de relacionamento atribuídas pelos próprios acadêmicos. Para que isso fosse possível, o trabalho apresentou uma revisão da literatura focada nas bases conceituais de redes sociais, redes formais e redes informais, e estudo de redes sociais e medidas específicas. O procedimento metodológico adotado foi o de uma pesquisa de estudo de campo, realizada por meio da análise de redes sociais, que tem foco estrutural, compreendendo tanto sua perspectiva macro quanto micro. Para tanto, foram utilizadas as medidas de centralidade (destrinchadas em grau, intermediação e proximidade), densidade e reciprocidade.

\section{QUADRO TEÓRICO}

Como definição básica, a palavra rede, originalmente provinda do latim retis, significa entrelaçado ou entrelaçamento de fios, remetendo à ideia de formação de ligações e de nós. Disso depreende-se a característica básica de uma rede, aplicada ao âmbito social, que são os relacionamentos existentes entre os diversos atores, que se envolvem em múltiplas relações de troca, 
seja como receptor e/ou ofertante (MEIRELLES et al., 2014). De forma semelhante, Bastos e Santos (2007) conceituam rede como interações entre os atores, cujo objetivo é a comunicação, a troca de conhecimentos e a ajuda mútua, criada por meio do compartilhamento de interesses e de situações vivenciada em comum.

Ainda que o trabalho pessoal em redes de conexões seja tão antigo quanto a história da humanidade, Marteleto (2001) ressalta que apenas nas últimas décadas passou-se a percebêlo e valorizá-lo como ferramenta organizacional. A autora argumenta, com base em Lipnack e Stamps (1992, p. 19), que a novidade dessa temática é a forma de análise, considerada como "global organizada", ou seja, que se baseia na experiência pessoal para conduzir uma perspectiva global, reconhecendo tanto a independência individual quanto a interdependência coletiva.

Em relação ao ambiente acadêmico, a temática de redes sociais ganha importância devido à crescente discussão acerca da interação em sala de aula, compondo o discurso de parte dos profissionais de ensino, que utilizam o termo integração-social para abordar a estratégia para promover e aprimorar a construção de conhecimentos por parte dos alunos (DAVIS; SILVA; ESPOSITO, 1989). Nesse sentido, as redes sociais tornaram-se bastante evidentes dentro das universidades em que os alunos, por meio de seus relacionamentos com os colegas, intensificam tanto sua rede de contatos profissionais, cooperando entre si para estudarem e realizarem trabalhos e atividades, bem como se relacionam no âmbito pessoal. Essas primeiras relações de âmbito profissional entendem-se como relações formais, enquanto que as segundas relações de âmbito pessoal são visualizadas como informais; conceitos que serão discutidos no subtópico a seguir.

\subsection{REDES FORMAIS E INFORMAIS}

O estudo da administração teve início com o interesse em se analisar o trabalho e temáticas subjacentes, como a sua produtividade ou seu rendimento, focando-se principalmente em termos de quantidade e tempo. Nesse contexto, por volta dos anos 1900, período marcado pela Administração Científica, focou-se estritamente nas relações formais presentes nas organizações, desconsiderando-se, assim, qualquer possibilidade de informalidade.

A possibilidade de existir informalidade nas relações intra-organizacionais só começou a ser considerada a partir de 1920, com os resultados advindos da Experiência ou Experimento de Hawthorne, realizado por Elton Mayo, dando base para o surgimento da segunda escola de administração, a Escola de Relações Humanas. Como consequência, ganha destaque a importância dos grupos sociais informais nas organizações, principalmente devido à evidência de seu impacto no trabalho.

A partir disso, evidenciou-se que existem basicamente dois tipos de redes intraorganizacionais, a rede formal e a rede informal (BASTOS; SANTOS, 2007; PASCOTTO et al., 2013; MEIRELLES et al., 2014; LEONARDO et al, 2019), cada qual com suas próprias características e implicações que serão exploradas a seguir.

Apesar do pioneirismo no estudo dos aspectos formais, e como consequência do 
crescente interesse nos aspectos informais, Régis, Bastos e Dias (2007) argumentam que - no contexto da análise de redes sociais - mais ênfase parece ser dada às relações informais, em detrimento das relações formais, ponderação que pretende ser superada nesse artigo.

Uma metáfora recorrentemente utilizada pela literatura (PASCOTTO et al., 2013; MEIRELLES et al., 2014; MCEVILY; SODA; TORTORIELLO, 2014) para diferenciar o aspecto formal e o informal das organizações é a analogia proposta por Krackhardt e Hanson (1993), que equipara a organização formal ao esqueleto da organização, enquanto que a informal é igualada ao sistema nervoso central. Ou seja, enquanto a primeira se configura como a estrutura oficial que organiza e regulamenta o comportamento, a segunda diz respeito aos processos do pensamento, ações e reações.

A rede social formal é caracterizada por uma estrutura de ligações prescrita previamente pela organização, com o objetivo de organizar, direcionar e padronizar os relacionamentos internos, de acordo com o estipulado no organograma organizacional. Em contrapartida, a rede social informal se configura pelas relações que surgem de maneira espontânea nas organizações, por meio da ação voluntária dos participantes, não obedecendo, assim, a nenhuma orientação previamente explicitada.

Essas duas redes não só se complementam, mas - mais importante - se influenciam. Pascotto et al. (2013), por exemplo, focou na influência da rede social informal sobre a rede formal. Segundo os autores, a rede social informal é fundamental para a formação de um ambiente de troca de conhecimento e informação. Bastos e Santos (2007) corroboram com esse argumento, defendendo que os relacionamentos informais permitem uma melhor circulação das informações, o que contribui para a articulação de entendimentos sobre o comportamento organizacional. Outras vantagens também são ressaltadas por Maciel e Camargo (2015), tais como o aumento do afeto positivo entre os colegas de trabalho, assim como seu senso de pertencimento e de identificação não só com eles, mas com a organização como um todo.

De uma maneira mais abrangente, Soda e Zaheer (2012), por sua vez, avaliaram a influência da consistência entre as redes formal e informal existentes na organização, tópico apontado por eles como ainda pouco explorado pela literatura. Os autores estabeleceram o termo consistência para a sobreposição ou convergência das redes formal e informal e encontraram evidências de que essa consistência está positivamente relacionada ao desempenho individual de seus atores, principalmente por permitir um aumento de acesso a informações, ideias e conhecimentos potencialmente diversos e valiosos, intensificado ainda mais pela reciprocidade das redes. Soda e Zaheer (2012) finalizam o trabalho indicando como pesquisa futura o estudo a respeito da combinação das características (atributos) dos atores com as características estruturais das redes. McEvily, Soda e Tortoriello (2014) endossam a necessidade de novos estudos que tratem a questão das redes intraorganizacionais de forma holística, abarcando tanto a rede formal quanto a informal, simultaneamente.

O estudo das redes de forma abrangente se apresenta como ainda mais importante em ambientes que demandam interação e troca de informação, ideias e conhecimentos, como é o 
caso das instituições de ensino de nível superior (TEIXEIRA, 2011). Acredita-se, assim, que se configura como lacuna de pesquisa o estudo das redes formal e informal entre graduandos de universidades, objeto de análise desse artigo.

\subsection{ANÁLISE DE REDES SOCIAIS}

A análise da estrutura das redes sociais possibilita um maior aprofundamento das relações existentes entre os atores envolvidos, explorando elementos como nós, posições, ligações e fluxos (GIGLIO; RYNGELBLUM, 2009; MEIRELLES et al., 2014). Segundo os autores, isso permite uma melhor compreensão de fatores como a estrutura geral das redes, a localização e a relevância dos atores, o grau de densidade de cada ator e a centralidade das conexões.

Em consonância com o defendido por Macambira (2009 como citado em SILVA; COSTA; ZAMBERLAN, 2011), a análise de rede social desse estudo tem foco estrutural, compreendendo tanto sua perspectiva macro quanto micro. Para tanto, utilizam-se as medidas de centralidade, poder e densidade. Ainda, dentro de centralidade, existem medidas específicas, como é o caso do grau (degree), intermediação (betweeness) e proximidade (closeness).

Uma das medidas de centralidade mede a quantidade de laços existentes entre os atores da rede (MARTELETO, 2001), permitindo entender o funcionamento geral da rede, em especial com a indicação do grau com que as relações estão centradas em cada um dos atores (PASCOTTO et al., 2013). A medida de centralidade contribui também ao trazer a ideia de poder dentro da rede. De acordo com Hanneman e Riddle (2005), é unanimidade que o poder se caracteriza como propriedade fundamental das estruturas sociais, sendo, assim, um importante fator a ser considerado nas redes sociais. Isso se justifica não só pelo fato do poder consistir em uma consequência dos padrões de relacionamento existentes entre os atores, mas, principalmente, devido à influência que pode exercer na rede, seja positiva ou negativa (HANNEMAN; RIDDLE, 2005).

A definição de grau (degree) consiste na quantidade de laços que os atores possuem com os demais integrantes da rede (WASSERMAN; FAUST, 1994). Sendo assim, atores que possuem mais vínculos têm maior grau, denotando, também, uma posição mais favorecida, que, como consequência, recebe mais informações e exerce maior influência na rede. Essa medida se divide em duas: indegree e outdegree, conforme o sentido do relacionamento (ligação).

A intermediação (betweeness) pode ser definida como uma interação dependente entre atores, quando um ator concentra o controle da comunicação, assumindo uma função de corretor de informação (TEIXEIRA, 2011). A intermediação está diretamente relacionada à medida de poder, visto que as relações acabam dependendo da vontade dos atores que concentram maior intermediação. Uma análise associada à intermediação consiste na identificação de possíveis caminhos geodésicos, ou seja, os caminhos mais curtos (alternativos) que podem ser seguidos por um determinado ator para se relacionar com os demais.

A proximidade (closeness), como o próprio nome sugere, analisa a distância (ou proximidade) existente entre os atores da rede, identificada 
por meio dos caminhos geodésicos. Dessa forma, altos valores de proximidade indicam uma melhor relação entre os atores da rede, enquanto que a baixa proximidade demonstra que os atores não se encontram bem relacionados entre si. Essa medida se divide em duas: incloseness e outcloseness conforme o sentido do relacionamento (ligação).

A densidade, por sua vez, refere-se ao número de ligações entre os indivíduos dispostos em uma rede, denotando, assim, o nível geral de conectividade e compartilhamento entre os atores (TEIXEIRA, 2011). Isso significa que quanto maior o número de pessoas que dizem se relacionar entre si em uma determinada rede, maior é a densidade dessa rede; enquanto que o contrário também é verdadeiro (menos relações indicam menor densidade).

A reciprocidade diz respeito ao grau em que os atores recorrem aos seus pares para se relacionarem denotando o quanto as relações são unidirecionais ou bidirecionais (WASSERMAN; FAUST, 1994; PETTERSON; CASTRO, 2016). Essa medida se mostra importante para determinar o sentido das relações (ligação), indicando se elas fluem em apenas um sentido ou em ambos (AZEVEDO; RODRIGUEZ, 2010). Dessa forma, a reciprocidade não se preocupa apenas em detectar a interligação dos atores, mas a mútua troca entre os pares.

\section{PROCEDIMENTOS METODOLÓGICOS}

O procedimento metodológico adotado foi uma pesquisa de estudo de campo, realizada por meio da análise de redes sociais, com foco estrutural, compreendendo tanto sua perspectiva macro quanto micro. Este trabalho tem como população todos os alunos universitários da instituição pesquisada, situada na região metropolitana da cidade de São Paulo. Os dados foram coletados de forma presencial, junto às classes de estudantes universitários do sexto semestre dos cursos de Administração e Ciências Contábeis, dois dentre os dez cursos mais procurados para graduação no país em 2015 (MARTINS, 2016). Essas classes foram denominadas de Turma 1 e Turma 2, respectivamente. A amostra foi não probabilística, escolhida por conveniência, e nas duas classes atingiu-se $90,2 \% \quad(n=55)$ e 90,6\% ( $n=48)$ dos alunos das turmas, respectivamente, segundo listas de chamada em vigor no momento da coleta de dados (agosto de 2016).

O questionário foi composto por três blocos: perfil dos respondentes, com perguntas sobre nome, idade e gênero; existência de relacionamento pessoal (informal) e profissional (formal) com cada um dos colegas da turma (sim/não); atribuição de nota para si mesmo a respeito do próprio relacionamento informal e formal (escala de $0 \mathrm{a}$ 10 , sendo zero nenhum relacionamento e 10 total relacionamento). A rede informal foi caracterizada como a rede estabelecida entre os alunos para tratarem de assuntos pessoais, não relacionados às disciplinas e/ou ao curso, enquanto que a rede formal foi caracterizada como a rede estabelecida entre os alunos para tratarem exclusivamente de assuntos profissionais, diretamente relacionados às disciplinas e/ou ao curso.

As notas que os participantes se atribuíram a respeito do nível de relacionamento informal e formal foram tabuladas e representadas por 
figuras geométricas, onde o círculo representa a faixa que compreende as notas de zero a quatro (nível inexistente ou baixo de relacionamento com os colegas de classe), o quadrado representa a faixa que compreende as notas de cinco a sete e o triangulo representa as notas de oito a dez (alto nível de relacionamento). Além disso, os alunos foram separados por gênero feminino e masculino, sendo o primeiro representado por figuras geométricas pintadas em vermelho e o segundo por figuras pintadas em azul.

As principais medidas adotadas foram as de centralidade (grau, intermediação e proximidade), densidade e reciprocidade para a comparação entre as características e medidas dos atores com as características estruturais das redes (SODA; ZAHEER, 2012). Como material de apoio, foram utilizados os programas NETDRAW (BORGATTI, 2002) para o mapeamento das redes sociais, bem como o UCINET (BORGATTI; EVERETT; FREEMAN, 2002) para a análise de suas medidas. Dessa forma, foi possível verificar tanto os aspectos descritivos dos relacionamentos (formal e informal) como realizar as análises estatísticas causais relacionadas a eles (HANNEMAN; RIDDLE, 2005). Ainda, dois testes estatísticos não paramétricos foram utilizados, o teste de correlação de Spearman, a fim de verificar as correlações significativas entre as medidas adotadas, e o teste de Wilcoxon, no intuito de comparar as medidas entre as redes formais e informais. Os testes não paramétricos são mais adequados para diversas situações de pesquisa uma vez que não exigem a normalidade dos dados.

\section{APRESENTAÇÃO E ANÁLISE DOS DADOS}

A seguir, são expostas as redes informais e formais dos cursos de Administração e Ciências Contábeis, respectivamente, nas Figuras 1, 2, 3 e 4 . A rede formada pelos alunos do curso de Administração (Turma 1) foi composta por 55 atores (taxa de resposta de 90,2\%), sendo 20 homens e 35 mulheres, com idade média de 24 anos (mínima 19 e máxima 46).

Figura 1 - Rede Informal da Turma 1 (Administração)

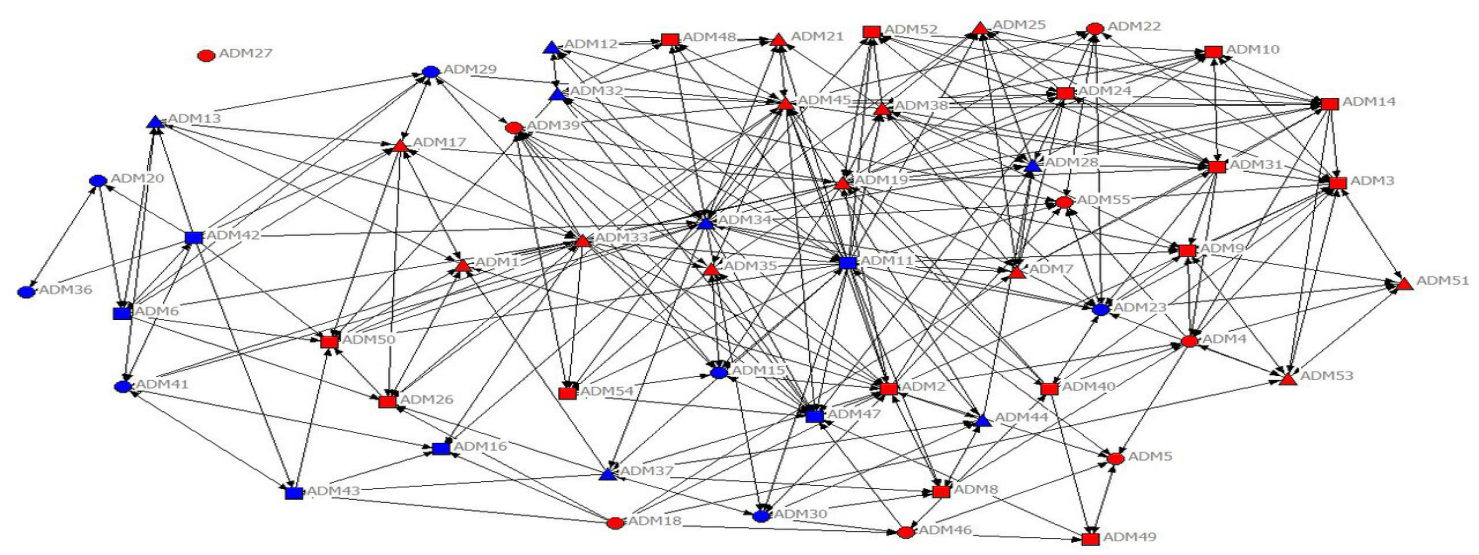

Nota: Legenda: Homens (azul)/Mulheres (vermelho); Notas de 0-4 (círculo), 5-7 (quadrado) e 8-10 (triângulo). 
Figura 2 - Rede formal da Turma 1 (Administração)

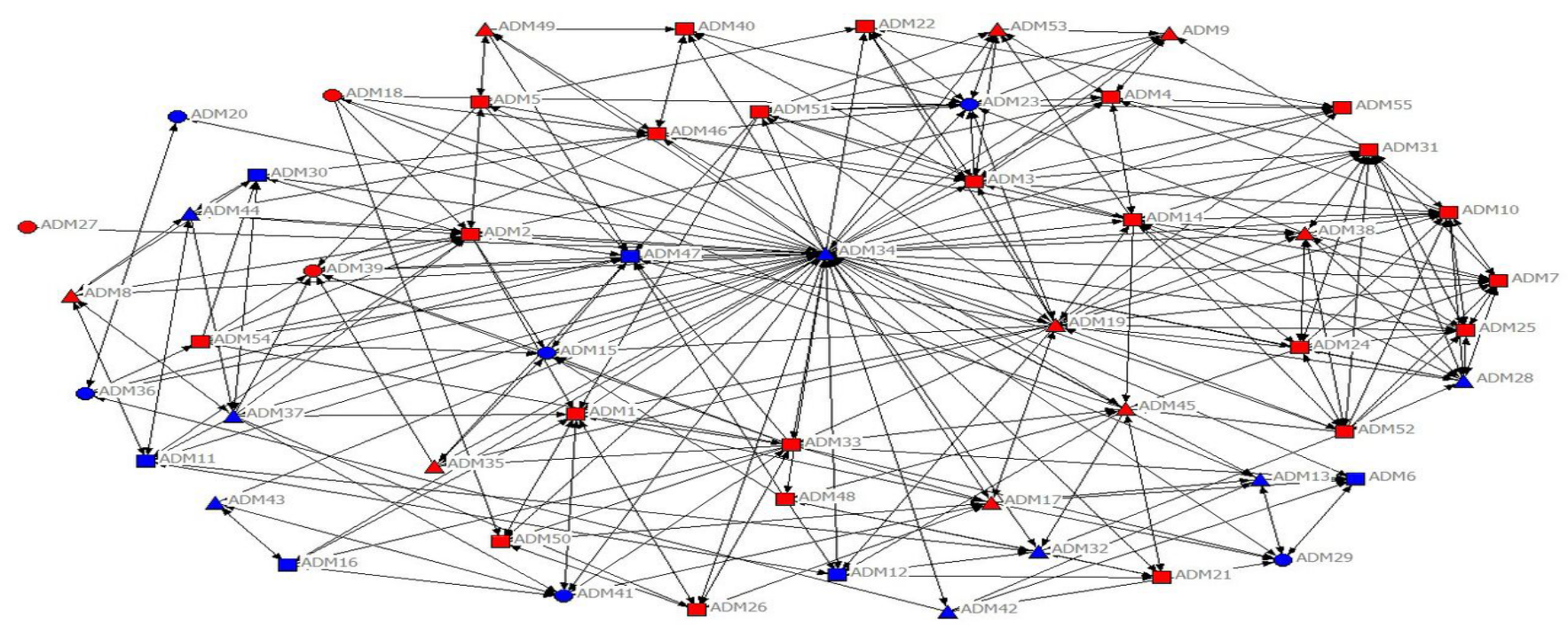

Fonte: Elaborado pelos autores.

Os desenhos das redes fornecem uma visão geral do que as medidas corroboraram. Exemplificando, a aluna caracterizada como ADM27 apareceu isolada na rede informal e, de fato, não foi citada pelos colegas, enquanto que na rede formal se relaciona com $A D M 2$, que serve de intermediário entre ela e os demais colegas. $O$ aluno ADM34 foi muito citado e indicou muitos colegas no relacionamento informal. Em relação à rede formal, embora a aluna ADM27 tenha mantido o posicionamento de não se relacionar com nenhum dos colegas (Outdegree), o aluno ADM34 pareceu se relacionar com ela formalmente (Indegree), bem como se destacou pelo número de relações com os demais alunos.

Já a rede formada pelos alunos do curso de Ciências Contábeis (Turma 2) foi composta por 48 atores (taxa de resposta de 90,6\%), sendo 17 homens e 31 mulheres, com idade média de 25 anos (mínima 19 e máxima 42).

Figura 3 - Rede Informal da Turma 2 (Ciências Contábeis)

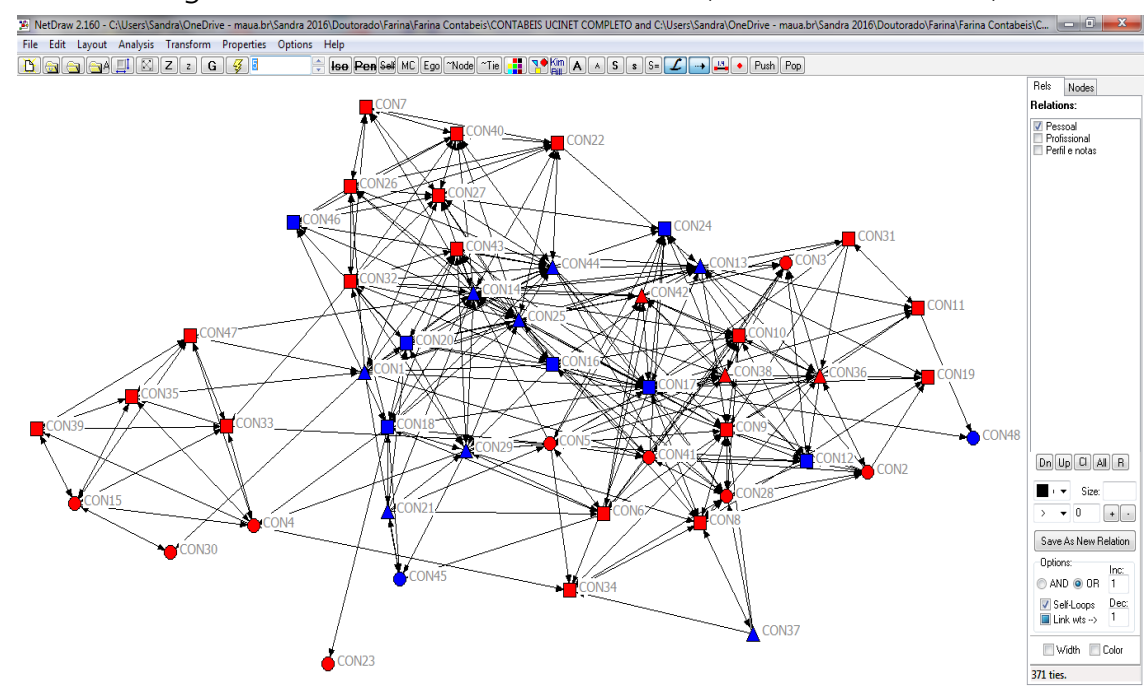

Fonte: Elaborado pelos autores. 
Figura 4 - Rede formal da Turma 2 (Ciências Contábeis)

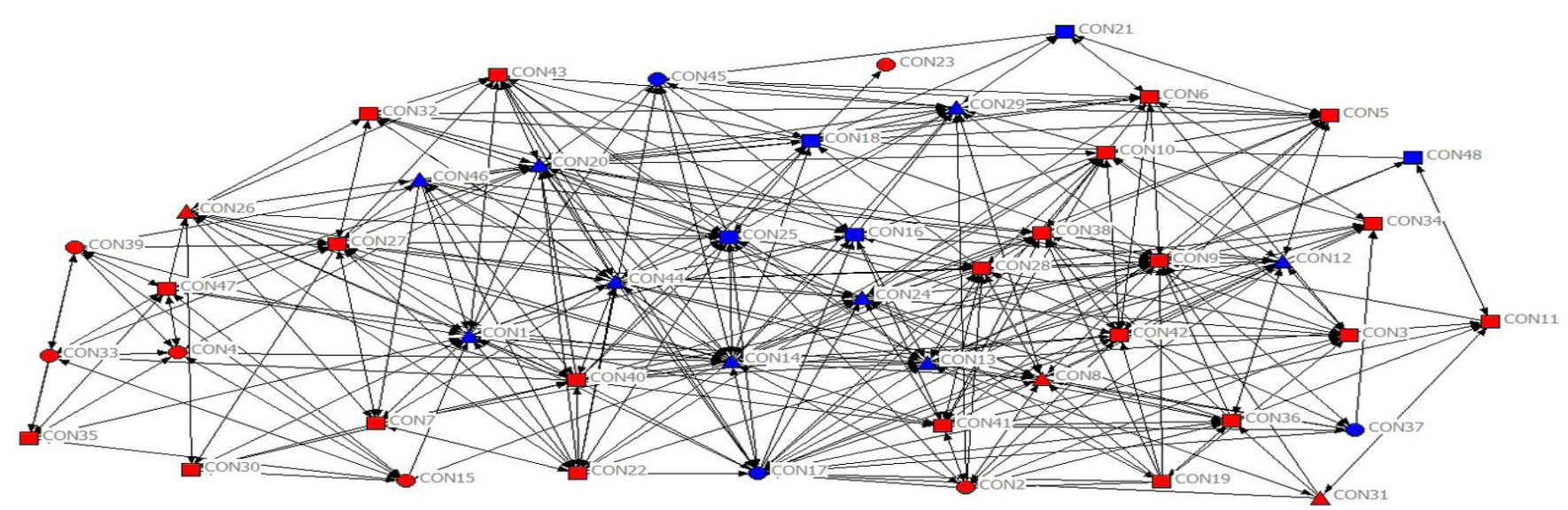

Fonte: Elaborado pelos autores.

Como exemplo da visão geral que os desenhos das redes oferecem, observou-se que na rede informal um único colega, caracterizado como CON18, se relacionou com a aluna CON23 (Indegree), enquanto que essa aluna não indicou nenhum colega (Outdegree). Essa mesma situação se repetiu em relação à rede formal. No lado oposto, o aluno CON14 foi muito citado e indicou muitos colegas, tanto no relacionamento informal como no formal.

\subsection{ATRIBUIÇÃO DE NOTA}

Analisando as notas atribuídas pelos alunos em termos de faixa, pôde-se observar que, em ambos os cursos, a maioria dos respondentes se concentrou na faixa intermediária (notas de 5 a 7), seguida da faixa superior (notas de 8 a 10), tanto para o relacionamento informal quanto formal. Esses dados aparecem no Tabela 1.

Em relação ao gênero, na Turma 1, pôdese observar uma melhor avaliação por parte das mulheres em ambos os relacionamentos formal e informal, em comparação aos homens. De fato, na rede informal, as alunas atribuem notas mais altas a si mesmas (77,2\% entre triângulos e quadrados, com média de 6,3$)$ do que os alunos do gênero masculino (65\%, com média 5,8). Essa maior avaliação entre as alunas ficou mais evidente na rede formal, já que as mulheres atingiram um percentual de 91,4\% entre triângulos e quadrados (média de $6,5)$, enquanto que os homens ficaram no patamar de 70\%. (média de 5,6). Dessa forma, no âmbito geral, foi verificada uma leve superioridade da rede formal $(83,6 \%)$ em relação à rede informal (77,2\%), indicando que ocorrem mais relacionamentos em relação aos assuntos profissionais, trabalhos escolares e estudo em conjunto.

Por outro lado, na Turma 2, o resultado foi o oposto, ou seja, observou-se uma melhor avaliação por parte dos homens em ambos os relacionamentos, em comparação às mulheres. $\mathrm{Ou}$ seja, maiores notas foram atribuídas pelos homens tanto no relacionamento informal $(88,3 \%$ entre triângulos e quadrados, com média de 6,9 ) quanto no formal $(82,3 \%$ e média de 7,0$)$, comparadas às notas dadas pelas alunas $(71,0 \%$ e média de 5,6 para a rede informal e $80,7 \%$ e média 6 para a rede 
formal). Sendo assim, de maneira igual à Turma 1, também para a Turma 2, no âmbito geral, foi verificada uma leve superioridade da rede formal $(81,3 \%)$ em relação à rede informal $(77,1 \%)$.

Tabela 1 - Notas atribuídas pelos alunos ao seu relacionamento com os colegas

\begin{tabular}{|c|c|c|c|c|c|c|}
\hline \multirow[b]{3}{*}{ Nota } & \multicolumn{6}{|c|}{ Administração - Turma 1} \\
\hline & \multicolumn{3}{|c|}{ Informal } & \multicolumn{3}{|c|}{ Formal } \\
\hline & Mulheres & Homens & Geral & Mulheres & Homens & Geral \\
\hline Faixa de 0 a 4 & $8(22,9 \%)$ & $7(35,0 \%)$ & $15(27,3 \%)$ & $3(8,6 \%)$ & $6(30,0 \%)$ & $9(16,4 \%)$ \\
\hline Faixa de 5 a 7 & $15(42,9 \%)$ & $6(30,0 \%)$ & $21(38,2 \%)$ & $23(65,7 \%)$ & $6(30,0 \%)$ & $29(52,7 \%)$ \\
\hline Faixa de 8 a 10 & $12(34,3 \%)$ & $7(35,0 \%)$ & $19(34,5 \%)$ & $9(25,7 \%)$ & $8(40,0 \%)$ & $17(30,9 \%)$ \\
\hline \multirow[t]{3}{*}{ Média } & 6,3 & 5,8 & 6,0 & 6,5 & 5,6 & 6,1 \\
\hline & \multicolumn{6}{|c|}{ Ciências Contábeis - Turma 2} \\
\hline & \multicolumn{3}{|c|}{ Informal } & \multicolumn{3}{|c|}{ Formal } \\
\hline Nota & Mulheres & Homens & Geral & Mulheres & Homens & Geral \\
\hline Faixa de 0 a 4 & $9(29,0 \%)$ & $2(11,8 \%)$ & $11(22,9 \%)$ & $6(19,4 \%)$ & $3(17,6 \%)$ & $9(18,8 \%)$ \\
\hline Faixa de 5 a 7 & $19(61,3 \%)$ & $7(41,2 \%)$ & $26(54,2 \%)$ & $22(71,0 \%)$ & $5(29,4 \%)$ & $27(56,3 \%)$ \\
\hline Faixa de 8 a 10 & $3(9,7 \%)$ & $8(47,1 \%)$ & $11(22,9 \%)$ & $3(9,7 \%)$ & $9(52,9 \%)$ & $12(25,0 \%)$ \\
\hline Média & 5,6 & 6,9 & 6,1 & 6,0 & 7,0 & 6,3 \\
\hline
\end{tabular}

Fonte: Elaborado pelos autores.

Verificou-se que as notas que os alunos atribuíram a si mesmos tanto para o relacionamento informal quanto para o formal, mostraram correlação estatisticamente significante (teste não paramétrico de Spearman) para ambos os cursos, sendo que no caso da Turma 1 a correlação pôde ser considerada forte $(S=0,747, p=0,000)$ e no caso da turma 2 a correlação foi considerada moderada $(S=0,496, p=0,000)$. Essa constatação indica que alunos com altas notas dadas para o relacionamento na rede formal também apresentam altas notas no relacionamento na rede formal e vice-versa.

Além disso, essas notas apresentaram correlação estatisticamente significativa com diversas das medidas adotadas nesse estudo, o que indica não só a consonância dessa mensuração com as demais, mas ressalta a importância de se têla utilizado. Essas correlações serão apresentadas nas análises de cada medida.

\subsection{GRAU (DEGREE)}

A definição de grau (degree) consiste na quantidade de laços que os atores possuem com os demais integrantes da rede (MARTELETO, 2001), e está dividida entre Indegree e Outdegree, sendo que o primeiro representa os alunos que são procurados pelos colegas para tratar de assuntos pessoais e/ou profissionais e o segundo representa os alunos que procuram os colegas. Ou seja, a medida Outdegree expressa a afirmação de que o aluno se relaciona com os demais alunos, no sentido de que ele busca o relacionamento, enquanto que a medida Indegree indica que esse aluno é procurado pelos demais colegas para se relacionar. Esses dados são expostos nos Tabelas 2 e 3.

Para a Turma 1 (Tabela 1), em relação à rede informal, pôde-se verificar que a medida de Indegree variou entre 0 a 13 ligações, sendo que a maioria 
dos atores (39) ficou em uma faixa intermediária (de 5 a 9 ligações). Nesse sentido, destacam-se alguns extremos, como é o caso dos atores 18 e 27, que não possuem nenhuma busca de vínculo por terceiros, assim como, em contrapartida, os alunos $19,34,45$ e 47 são os mais procurados, sendo que os dois primeiros tiveram correspondência de 11 colegas e o terceiro e o quarto com 12 e 13 colegas, respectivamente. A medida Outdegree teve uma maior variação, entre 0 a 26 ligações, sendo que a maioria dos atores (29) se concentrou em uma faixa inferior (de 2 a 5 ligações). Também nesse caso destacam-se alguns extremos, como o aluno 27, que não procurou estabelecer contato com nenhum colega, e o aluno 36, que buscou apenas um colega. Por outro lado, o aluno 11 buscou estabelecer contado com 26 colegas, seguido do aluno 34, que buscou contato com 20 colegas.

Para a rede formal, verificou-se que a medida Indegree variou entre 1 a 13 ligações, com a maioria dos atores (38) dispostos em uma faixa intermediária (de 4 a 9 ligações). Também aqui se destacam alguns extremos, como os alunos 18, 27 e 42, que possuem apenas um contato vindo dos demais colegas, e o aluno 20 que recebe apenas um contato, enquanto que, por outro lado, os alunos 3 e 34 são os atores mais procurados pelos colegas, somando 13 contatos para cada um, seguido do aluno 47, com 12 ligações, e os alunos 1, 2, 10, 19 e 23, com 11 ligações. A medida de Outdegree da rede formal também teve maior variação, entre 0 a 54 ligações, com a maioria dos atores (43) se concentrando em uma faixa entre inferior e intermediária (de 2 a 8 ligações). Nesse caso, observaram-se atores sem nenhuma ligação, como é o caso do aluno 27 , seguido do aluno
20, que procura somente um dos colegas para estabelecer vínculos. Por outro lado, destaca-se o aluno 34 como o que possui a maior quantidade, totalizando 54 colegas procurados por ele para estabelecer relacionamentos profissionais, mais do que o dobro do segundo colocado nesse quesito, o aluno 19, com 21 ligações.

As medidas de indegree e outdegree não apresentaram diferenças significativas entre as redes informal e formal para a Turma 1 (teste de Wilcoxon). Isto é, os números médios de ligações recebidas por aluno são semelhantes entre as redes formais e informais, assim como os números médios de ligações realizadas, sendo de 6,7 para a rede informal e 6,8 para a formal na turma de Administração.

Quando se testa se há correlação entre a nota atribuída pelo aluno ao relacionamento informal com a suas medidas indegree e oudegree, o resultado indica correlação positiva estatisticamente significativa, ainda que fraca, tanto na rede informal quanto na rede profissional (informal $S=0,342, p=0,011$ e $S=0,394, p=0,003$, respectivamente; e formal $S=0,270, p=0,046$ e $S=0,294, p=0,029$, respectivamente). A nota atribuída ao relacionamento formal mostrou correlação semelhante, ou seja, positiva estatisticamente significativa, também fraca, com o outDegree pessoal $(S=0,369, p=0,006)$. Os resultados indicam que há uma relação entre a avaliação feita pelo aluno a respeito do seu relacionamento com o número de relações que ele faz com seus colegas na turma, isto é, se a nota é alta a quantidade de ligações também é alta e vice-versa. 
Tabela 2 - Indegree e Outdegree das redes informal e formal - Administração

\begin{tabular}{|c|c|c|c|c|c|c|c|}
\hline \multicolumn{4}{|c|}{ Informal } & \multicolumn{4}{|c|}{ Formal } \\
\hline Atores & $I n$ & Atores & Out & Atores & In & Atores & Out \\
\hline 18,27 & 0 & 27 & 0 & $18,27,42$ & 1 & 27 & 0 \\
\hline $20,36,42$ & 2 & 36 & 1 & 20 & 2 & 20 & 1 \\
\hline 40,49 & 3 & $\begin{array}{l}5,8,16,20,41, \\
50,55\end{array}$ & 2 & $36,43,49$ & 3 & $13,29,35,39,43$ & 2 \\
\hline 11,13 & 4 & $\begin{array}{l}7,22,25,26,43, \\
49,54\end{array}$ & 3 & $5,16,37,48,54$ & 4 & $\begin{array}{l}6,15,16,22,36, \\
40,50,55\end{array}$ & 3 \\
\hline $\begin{array}{l}5,6,16,29,30,37, \\
43,44,46,51\end{array}$ & 5 & $\begin{array}{l}1,9,12,15,35 \\
39,46,47,51\end{array}$ & 4 & $21,26,35,40$ & 5 & $12,26,44,47,49$ & 4 \\
\hline $\begin{array}{l}8,12,22,32,33 \\
41,48,54\end{array}$ & 6 & $\begin{array}{l}21,29,30,48 \\
52,53\end{array}$ & 5 & $\begin{array}{l}6,8,9,13,22,29, \\
30,33,44,50,51, \\
55\end{array}$ & 6 & $\begin{array}{l}1,8,9,21,30,32, \\
41,42,53\end{array}$ & 5 \\
\hline $4,17,21,26,53$ & 7 & $6,13,17$ & 6 & $\begin{array}{l}11,12,24,32,41, \\
46,52,53\end{array}$ & 7 & $\begin{array}{l}4,5,7,10,11,18, \\
4554\end{array}$ & 6 \\
\hline $\begin{array}{l}10,14,15,24,25, \\
31,35,55\end{array}$ & 8 & $10,18,40,44$ & 7 & $4,15,17,38,45$ & 8 & 48 & 7 \\
\hline $\begin{array}{l}1,7,9,23,38,39, \\
50,52\end{array}$ & 9 & $3,4,23,32,37$ & 8 & $7,25,28,39$ & 9 & $\begin{array}{l}2,17,23,25,28, \\
37,51\end{array}$ & 8 \\
\hline $2,3,28$ & 10 & 28 & 9 & 14,31 & 10 & $3,38,46$ & 9 \\
\hline 19,34 & 11 & 42 & 10 & $1,2,10,19,23$ & 11 & 24,52 & 10 \\
\hline 45 & 12 & 14 & 12 & 47 & 12 & 14,31 & 12 \\
\hline 47 & 13 & $24,38,45$ & 13 & 3,34 & 13 & 33 & 14 \\
\hline & & 31 & 14 & & & 19 & 21 \\
\hline & & 2 & 15 & & & 34 & 54 \\
\hline & & 33 & 16 & & & & \\
\hline & & 19 & 17 & & & & \\
\hline & & 34 & 20 & & & & \\
\hline & & 11 & 26 & & & & \\
\hline
\end{tabular}

Fonte: Elaborada pelos autores.

Para a Turma 2 (Tabela 3), em relação à rede informal, pôde-se verificar que a medida de Indegree variou entre 1 a 16 ligações, sendo que a maioria dos atores (31) ficou em uma faixa intermediária (de 5 a 10 ligações). Novamente alguns extremos puderam ser observados, como os atores 23 e 37, alunos com a menor quantidade de busca de vínculos, e, por sua vez, os alunos 9 e 14 que apresentam a maior quantidade, tendo sido procurados por 16 colegas cada. A medida de Outdegree teve uma maior variação, entre 0 a 21 ligações, não havendo uma concentração de atores numa faixa específica. Nesse caso, destacam-se os alunos 23, 24 e 48, que não procuram estabelecer contato com nenhum colega, seguidos dos alunos 19, 30 e 45 que buscam contato apenas com um colega. Na outra ponta estão os alunos 14 e 25, que estabelecem contato com 21 colegas.

Para a rede formal, a medida de indegree variou entre 0 e 18 ligações, com uma concentração de atores (32) em uma faixa entre inferior e intermediária (de 4 a 10 ligações). Nos opostos, identificou-se o aluno 23 com apenas um contato vindo dos demais colegas e os alunos 19 e 31 com dois contatos cada, enquanto que, por outro lado, os alunos 1 e 13 são os atores mais procurados pelos colegas, somando 18 contatos para cada um deles, seguidos dos alunos 14 e 
24, procurados por 17 colegas, e dos alunos 9 e 29, procurados por 16 colegas. Em relação ao outdegree, a variação também foi maior, entre 0 a 27 ligações, concentrando a maioria dos atores (34) em uma faixa intermediária (de 5 a 12 ligações). Nesse caso, os opostos foram o aluno 23, que não busca nenhum colega para estabelecer contato profissional, e, por sua vez, o aluno 14, que procura 27 colegas.

Na turma de Contabilidade o número médio de ligações foi de 7,7 na rede informal e 9,3 na rede formal. Além disso, foi verificado que as medidas de inDegree e outDegree apresentaram diferenças significativas entre as relações informal e formal $(Z=-4,000, p=0,000$ e $Z=-2,344, p=0,019$, respectivamente), verificadas por meio do teste não paramétrico de Wilcoxon, isto é, os resultados do degree do relacionamento informal foram menores que do relacionamento formal, indicando que os alunos têm mais relacionamento na rede formal do que na informal.
As correlações para essa turma foram ainda mais expressivas. A nota que cada aluno atribuiu a si mesmo a respeito do seu relacionamento pessoal mostrou correlação positiva estatisticamente significativa e considerada moderada com os inDegree e outDegree pessoal $(S=0,417, p=0,003$ e $S=0,566, p=0,000$, respectivamente). Isto é, se o aluno confere a si mesmo uma nota alta, a quantidade de alunos que o procuram na relação informal também é alta e o mesmo ocorre quando o próprio aluno se relaciona informalmente com os demais. No relacionamento formal a correlação ocorreu tanto quando os colegas procuram o aluno e quando o aluno procura pelos colegas, pois, a nota atribuída ao relacionamento formal mostrou correlação positiva estatisticamente significativa moderada para os valores de inDegree e outDegree profissional $(S=0,536, p=0,000$ e $S=0,425$, $p=0,003$, respectivamente).

Tabela 3 - Indegree e Outdegree das redes informal e formal - Ciências Contábeis

\begin{tabular}{|c|c|c|c|c|c|c|c|}
\hline \multicolumn{4}{|c|}{ Informal } & \multicolumn{4}{|c|}{ Formal } \\
\hline Atores & $I n$ & Atores & Out & Atores & In & Atores & Out \\
\hline 23,37 & 1 & $23,24,48$ & 0 & 23 & 1 & 23 & 0 \\
\hline $30,31,48$ & 2 & $19,30,45$ & 1 & 19,31 & 2 & $4,24,30$ & 3 \\
\hline 2 & 3 & 28,34 & 3 & 37,48 & 3 & 35,48 & 4 \\
\hline 11,39 & 4 & $7,33,35,37,39$ & 4 & $11,21,39$ & 4 & $3,7,21,31,42$ & 5 \\
\hline $4,19,21,34,45$ & 5 & $9,31,46$ & 5 & $2,33,34$ & 5 & $11,33,37$ & 6 \\
\hline $7,15,33,35,47$ & 6 & $4,11,15,40,47$ & 6 & $30,35,46$ & 6 & $15,34,38,39,45$ & 7 \\
\hline 6,3 & 7 & $12,13,21,26$ & 7 & $4,15,40,47$ & 7 & $8,13,16,47$ & 8 \\
\hline $\begin{array}{l}3,10,12,22,25,32, \\
40,41,46\end{array}$ & 8 & 41 & 8 & $7,36,41,45$ & 8 & $5,9,25,36$ & 9 \\
\hline $5,16,24,26,42,43$ & 9 & $2,8,20,22$ & 9 & $6,22,26$ & 9 & $10,19,32,43$ & 10 \\
\hline $8,18,27,36$ & 10 & $6,27,43$ & 10 & $\begin{array}{l}3,5,10,12,16,32, \\
43\end{array}$ & 10 & $1,2,6,41$ & 11 \\
\hline 1,20 & 11 & $\begin{array}{l}1,16,29,36,38, \\
42\end{array}$ & 11 & 44 & 11 & $12,17,22,26,29$ & 12 \\
\hline $13,28,44$ & 12 & 10 & 12 & $8,18,28,42$ & 12 & 46 & 13 \\
\hline 29 & 13 & 18,32 & 13 & 27 & 13 & 18 & 14 \\
\hline 17 & 14 & 44 & 15 & 20 & 14 & 27,28 & 15 \\
\hline \multirow[t]{4}{*}{9,14} & 16 & 5 & 16 & $17,25,38$ & 15 & 20 & 16 \\
\hline & & 17 & 18 & 9,29 & 16 & 44 & 19 \\
\hline & & 14,25 & 21 & 14,24 & 17 & 40 & 20 \\
\hline & & & & 1,13 & 18 & 14 & 27 \\
\hline
\end{tabular}

Fonte: Elaborada pelos autores. 


\subsection{INTERMEDIAÇÃO (BETWEENNESS)}

A medida de Intermediação (Betweenness) revela onde ocorre a concentração do controle dos relacionamentos, no sentido de mostrar o quanto um ator intermedia as relações entre seus pares (TEIXEIRA, 2011). Sendo assim, quanto maior a medida de intermediação, mais um ator tem poder nas relações entre os pares da rede. Os Tabelas $4 \mathrm{e}$ 5 expõem os valores dessas medidas para as redes formal e informal estabelecidas entre os alunos de cada um dos cursos analisados.

Em relação à Turma 1(Tabela 4), analisando a rede informal, observou-se que a maioria dos atores (42) apresenta baixo índice de intermediação, variando entre $0,02 \%$ e $5,52 \%$. Nos extremos, têm-se os atores 12, 18, 27 e 36, que não possuem nenhum grau de intermediação, enquanto que os alunos 2 e 19 se encontram no oposto, estando alocados na faixa que varia de 15,28\% a $17,72 \%$, com destaque, ainda, para o ator 34 , que possui o maior percentual de intermediação, com $26,31 \%$ (ator com maior poder na rede). Resultado semelhante se repete na rede formal, com a maior concentração de alunos (45) alocados em uma faixa com baixo índice de intermediação, variando entre $0,034 \%$ e $5,0173 \%$. Verificando os extremos, têm-se os atores 18, 20, 27, 42 e 43, que não possuem nenhum grau de intermediação, e, em contrapartida, os atores 19 e 34 se destacam na porcentagem de intermediação, com 15,91\% e, mais expressivo, 49,93\% de intermediação, respectivamente. Além de deter o maior poder nas duas redes, o aluno 34 é um intermediário em praticamente $50 \%$ dos relacionamentos entre os pares de colegas na rede formal.

A medida betweeness apresentou diferença significativa entre as relações pessoais e profissionais apenas para a Turma $1 \quad(Z=-2,359, p=0,018)$, verificada por meio do teste não paramétrico de Wilcoxon, indicando que as intermediações podem ser consideradas diferentes nas redes formal e informal, sendo maior para o relacionamento pessoal (valor médio de intermediação $M=9,0$ ) do que para o profissional $(M=8,0)$. Uma correlação positiva moderada estatisticamente significativa (teste de Spearman) entre essas medidas também foi verificada $(S=0,501, p=0,000)$, indicando uma relação linear entre as medidas.

Tabela 4 - Betweenness das redes informal e formal - Administração

\begin{tabular}{|c|c|c|c|}
\hline \multicolumn{2}{|c|}{ Informal } & \multicolumn{2}{|c|}{ Formal } \\
\hline Atores & Bebveenness & Atores & Betweenness \\
\hline $12,18,27,36$ & 4 atores $(0 \%)$ & $18,20,27,42,43$ & 5 atores $(0 \%)$ \\
\hline $\begin{array}{l}7,8,9,13,16,21,22, \\
25,26,35,39,41,48, \\
49,51,52,53,54\end{array}$ & 18 atores $(0,02-0,77 \%)$ & $\begin{array}{l}5,7,8,9,10,12,13,15,16 \\
21,22,24,25,26,28,29 \\
31,32,35,37,38,40,44, \\
48,49,52,53\end{array}$ & 27 atores $(0,03-0,93 \%)$ \\
\hline $\begin{array}{l}1,5,10,14,20,24, \\
28,29,30,31,32,37, \\
38,44,47,55\end{array}$ & 16 atores $(1,00-2,72 \%)$ & $3,4,14,30,36,47,51,55$ & 8 atores $(1,02-2,6 \%)$ \\
\hline $\begin{array}{l}3,4,6,11,17,40,43, \\
46\end{array}$ & 8 atores $(3,09-5,52 \%)$ & $\begin{array}{l}1,2,6,11,33,41,45,46 \\
50,55\end{array}$ & 10 atores $(3,02-5,02 \%)$ \\
\hline $15,23,33,42,45,50$ & 6 atores $(6,13-10,20 \%)$ & $17,23,39$ & 3 atores $(7,37-10,16 \%)$ \\
\hline 2,19 & 2 atores $(15,28-17,72 \%)$ & 19 & 1 ator $(15,91 \%)$ \\
\hline 34 & 1 ator $(26,31 \%)$ & 34 & 1 ator $(49,93 \%)$ \\
\hline
\end{tabular}

Fonte: Elaborada pelos autores. 
Em relação à Turma 2 (Tabela 5), observase que a maioria dos atores da rede informal (42) apresenta baixo índice de intermediação, variando entre $0 \%$ e 5,42\%. Nos extremos, verificam-se seis alunos que não possuem nenhum grau de intermediação, os atores 3, 19, 23, 24, 39 e 48, assim como, por outro lado, os alunos 14 e 1 se destacam como os alunos com maior grau de intermediação, 13\% e 15,6\%, respectivamente. Resultado semelhante foi encontrado na rede formal, com grande concentração dos alunos (43) em faixas com baixos índices de intermediação, entre $0,02 \%$ e 5,58\%. Nos opostos, tem-se o aluno 23 com o grau mais baixo de intermediação e o aluno 14 com o mais alto grau, de 17,56\%.

Diferente da Turma 1, as medidas de intermediação não apresentaram diferenças significativas entre as redes formal e informal (teste não paramétrico de Wilcoxon). Apesar de as médias de intermediação não serem consideradas diferentes nas duas redes, seus valores considerados por aluno indicaram uma relação linear, com uma correlação positiva e estatisticamente significante encontrada entre elas (teste de Spearman), considerada forte $(S=0,620, p=0,000)$. Além disso, a nota atribuída ao relacionamento pessoal mostrou correlação positiva estatisticamente significativa moderada com a medida Betweenness pessoal $(S=0,41, p=0,003)$, assim como a nota atribuída ao relacionamento profissional mostrou correlação positiva estatisticamente significativa moderada para o Betweenness profissional $(S=0,486$, $\mathrm{p}=0,000)$.

Tabela 5 - Betweenness das redes informal e formal - Ciências Contábeis

\begin{tabular}{|c|c|c|c|}
\hline \multicolumn{2}{|c|}{ Informal } & \multicolumn{2}{|c|}{ Formal } \\
\hline Atores & Betweenness & Atores & Betweenness \\
\hline $3,19,23,24,39,48$ & 6 atores $(0 \%)$ & 23 & 1 ator $(0 \%)$ \\
\hline $\begin{array}{l}2,6,7,10,11,12,13,15, \\
16,20,21,22,26,27,28, \\
30,31,32,33,34,37,38, \\
40,42,43,45,46\end{array}$ & $\begin{array}{l}27 \text { atores } \\
(0,01-2,87 \%)\end{array}$ & $\begin{array}{l}2,3,4,5,6,7,8,11,12,15 \\
16,19,21,22,24,25,26,30 \\
31,32,33,34,35,36,37,38 \\
39,41,42,43,45,46,47,48\end{array}$ & $\begin{array}{l}34 \text { atores } \\
(0,02-2,94 \%)\end{array}$ \\
\hline $\begin{array}{l}4,9,18,29,35,36,41,44, \\
47\end{array}$ & $\begin{array}{l}9 \quad \text { atores } \quad(3,01- \\
5,42 \%)\end{array}$ & $\begin{array}{l}9,10,17,20,27,28,29,40 \\
44\end{array}$ & 9 atores $(3,69-5,58 \%)$ \\
\hline $5,8,17,25$ & $\begin{array}{l}4 \quad \text { atores } \quad(6,06- \\
10,67 \%)\end{array}$ & $1,13,18$ & 3 atores $(6,69-9,88 \%)$ \\
\hline 14 & 1 ator $(13,01 \%)$ & 14 & 1 ator $(17,56 \%)$ \\
\hline 1 & 1 ator $(15,60 \%)$ & & \\
\hline
\end{tabular}

Fonte: Elaborada pelos autores. 


\subsection{PROXIMIDADE (CLOSENESS)}

A medida closeness se refere ao grau de proximidade que um ator está em relação aos outros atores da rede, ou seja, quanto maior a pontuação, maior é o grau de proximidade desse ator. Assim como o degree, essa medida também se divide em incloseness e outcloseness, indicando a aproximação quando os colegas buscaram relacionamento com um aluno (incloseness) e quando o aluno buscou relacionamento com os demais colegas (outcloseness). Essa medida é expressa em porcentagem e indica de quantos atores da rede determinado ator está próximo. As referidas medidas das redes pessoal e profissional de ambos os cursos seguem expostas nos Tabelas 6 e 7, respectivamente.

Acerca da Turma 1(Tabela 6), em relação à rede informal, observa-se que a maior parte dos atores está concentrada na faixa intermediária, variando de 20 a $30 \%$ para o incloseness e de 15 a $30 \%$ para o outcloseness. $O$ ator com o menor percentual de proximidade tanto no incloseness quanto no outcloseness é o ator 27. Já a ator 18 possui medida incloseness na faixa de 1 a $2 \%$, porém o outcloseness está na faixa de 30,1 a 31\%, ou seja, a indicação do aluno pelos colegas faz com que ele não esteja próximo deles, porém, a indicação que o aluno faz em relação aos colegas o torna mais próximo deles. Constata-se, assim, uma diferença entre as percepções de relacionamento informal na rede. Resultado semelhante foi encontrado para a rede formal, já que a maior parte dos atores (40) está concentrada na faixa de 25 a 30\% na medida de incloseness, sendo a menor pontuação no valor de $2 \%$. Na medida outcloseness foram criadas mais faixas para enquadramento dos atores, pois há grande variação na pontuação de cada um deles. Sendo assim, observa-se que a maior parte dos atores está distribuída em duas faixas superiores, estando 18 atores entre 30,1 e $40 \%$ e 17 entre 40,1 a $50 \%$. Ainda, destaca-se o ator 27, disposto na faixa de 1 a $2 \%$, assim como, por outro lado, o ator 34 , com outcloseness de $100 \%$.

As medidas de inCloseness e outCloseness da turma de Administração apresentaram diferenças significativas entre as relações pessoais e profissionais, verificadas por meio do teste não paramétrico de Wilcoxon $(Z=-5,661, p=0,000$ e $Z=-$ $6,393, p=0,000$, respectivamente). Curiosamente, houve divergência em relação às médias dessas medidas, sendo que no caso da rede pessoal o incloseness $(M=26,2)$ foi maior que o outcloseness $(21,5)$, enquanto que na rede formal o contrário se mostrou verdadeiro, ou seja, o outcloseness $(71,7)$ foi maior que o incloseness $(M=30,0)$.

Além disso, a nota atribuída ao relacionamento pessoal mostrou correlação positiva estatisticamente significativa, ainda que fraca, com o incloseness e outcloseness pessoal $(S=0,266$, $p=0,049$ e $S=0,335, p=0,012$, respectivamente), enquanto que a nota atribuída ao relacionamento profissional mostrou correlação positiva estatisticamente significativa, também fraca, apenas com o outcloseness ( $S=0,266, p=0,050)$, indicando que a percepção de cada aluno difere das percepções dos demais em relação a ele. 
Tabela 6 - Closeness das redes informal e formal - Turma 1 (Administração)

\begin{tabular}{|c|c|c|c|}
\hline \multicolumn{4}{|c|}{ Informal } \\
\hline Atores & Incloseness & Atores & Outcloseness \\
\hline 18,27 & $\begin{array}{l}2 \text { atores } \\
\text { (Faixa } 1-2 \%)\end{array}$ & 27 & $\begin{array}{l}1 \text { ator } \\
\text { (Faixa 1-2\%) }\end{array}$ \\
\hline $\begin{array}{l}3,4,5,6,7,8,9,10,11,12,13, \\
14,15,16,17,20,21,22,23,24, \\
25,26,29,30,31,32,33,36,37, \\
38,40,41,42,43,44,46,48,49, \\
50,51,52,53,54,55\end{array}$ & $\begin{array}{l}44 \text { atores } \\
\text { (Faixa 20- } \\
30 \% \text { ) }\end{array}$ & $\begin{array}{l}1,2,3,4,5,6,7,8,9,10,11,12, \\
13,14,15,16,17,19,20,21,22, \\
23,24,25,26,28,29,30,31,32, \\
33,34,35,36,37,38,39,40,41, \\
42,43,44,45,46,47,48,49,50, \\
51,52,53,54,55\end{array}$ & $\begin{array}{l}53 \text { atores } \\
\text { (Faixa } 15-30 \% \text { ) }\end{array}$ \\
\hline $1,2,19,28,34,35,39,45,47$ & $\begin{array}{l}9 \text { atores (Faixa } \\
30,1-33 \%)\end{array}$ & 18 & $\begin{array}{l}1 \text { ator (Faixa } \\
30,1-31 \%)\end{array}$ \\
\hline \multicolumn{4}{|c|}{ Formal } \\
\hline Atores & Incloseness & Atores & Outcloseness \\
\hline $\begin{array}{l}4,5,6,7,8,9,11,12,13,14,16, \\
18,20,21,22,24,25,26,28,29, \\
30,31,32,36,37,38,40,41,42, \\
43,44,46,48,49,50,51,52,53, \\
54,55\end{array}$ & $\begin{array}{l}40 \text { atores } \\
\text { (Faixa } 25- \\
30 \% \text { ) }\end{array}$ & 27 & $\begin{array}{l}1 \text { ator } \\
\text { (Faixa } 1-2 \%)\end{array}$ \\
\hline \multirow[t]{5}{*}{$\begin{array}{l}1,2,3,10,15,17,19,23,27,33 \\
34,35,39,45,47\end{array}$} & $\begin{array}{l}15 \text { atores } \\
\text { (Faixa } 30,1- \\
34 \%)\end{array}$ & $13,16,20,29,43$ & $\begin{array}{l}5 \text { atores } \\
\text { (Faixa } 23-30 \% \text { ) }\end{array}$ \\
\hline & & $\begin{array}{l}1,5,6,8,9,10,15,22,26,30,35 \\
36,40,41,44,47,49,53\end{array}$ & $\begin{array}{l}18 \text { atores } \\
\text { (Faixa } 30,1-40 \% \text { ) }\end{array}$ \\
\hline & & $\begin{array}{l}2,3,4,7,14,17,24,25,28,31,33, \\
37,38,46,51,52,54\end{array}$ & $\begin{array}{l}17 \text { atores } \\
\text { (Faixa } 40,1-50 \% \text { ) }\end{array}$ \\
\hline & & $\begin{array}{l}11,12,18,19,21,23,32,39,42 \\
45,48,50,55\end{array}$ & $\begin{array}{l}13 \text { atores } \\
\text { (Faixa } 50,1-63 \%)\end{array}$ \\
\hline & & 34 & 1 ator $(100 \%)$ \\
\hline
\end{tabular}

Fonte: Elaborada pelos autores.

Em relação à Turma 2 (Tabela 7), na rede informal, observa-se que a variação na pontuação do incloseness não foi grande, com todos os atores concentrados na faixa de 14 a 20\%. Diferentemente de todas as demais medidas, não houve atores com pontuação extremamente alta e nem baixa. Já para o outcloseness a variação pode ser considerada mais expressiva, já que vai da faixa de 1 a $3 \%$ até a faixa de 61 a $63 \%$. Nesse sentido, a maior parte dos atores (41) está alocada nas duas faixas entre 22,0 e $60 \%$. Há, ainda, quatro atores na menor faixa, de 1 a $3 \%$, além de três atores na maior faixa, de 61 a $63 \%$. Observa-se, também, que os atores 3 e
24 possuem a maior discrepância entre essas duas medidas, possuindo um incloseness na faixa de 19 a 20\%, mas um outcloseness na faixa de 1 a 3\%, ou seja, os colegas se consideram próximos a eles, porém o inverso não ocorre.

$\mathrm{Na}$ rede formal o resultado se repete, novamente com uma variação pequena do incloseness, com todos os atores concentrados na faixa de 25,0 a $38 \%$, sendo que nenhum ator se destaca com um percentual extremamente alto ou baixo. No caso do outcloseness, a variação pode ser considerada maior, variando entre as faixas de 1,0 a 3,0\% ATÉ 61 a 71\%. Nesse intervalo, a maior parte 
dos atores (44) está disposta nas faixas entre 29,0 a 60,0\%. Ainda, há apenas o ator 23 na menor faixa, entre 1,0 e 3,0\%, assim como os atores 10, 40 e 44 na maior faixa, entre 61,0 e $71,0 \%$.

Observa-se, também, que os atores 23 e 44 possuem a maior discrepância entre o incloseness e o outcloseness, visto que ambos possuem a medida incloseness na faixa de $30,1 \%$ a $35,0 \%$ respectivamente, porém 0 ator 23 tem um outcloseness na faixa de 1 a $3 \%$, enquanto que o 44, por outro lado, está na maior faixa, de 61 a $71 \%$. Ou seja, em ambos os casos, os colegas se consideram próximos a eles, quando indicam que se relacionam, porém o aluno 23 não tem uma tendência voltada à aproximação, enquanto que o aluno 44 se considera muito mais próximo aos colegas.

Também para as medidas de incloseness e outcloseness da Turma 2 foram encontradas diferenças significativas entre as relações pessoais e profissionais, verificadas por meio do teste não paramétrico de Wilcoxon $(Z=-6,031, p=0,000$ e $Z=-$ 2,867, $p=0,002$, respectivamente). Para a Turma 1 houve consonância com a turma 2 , em relação às médias dessas medidas, sendo que tanto na rede pessoal quanto na rede profissional o outcloseness (valor médio $M=40,7$ e $M=45,9$, respectivamente) foi maior que o incloseness $(M=16,2$ e $M=32$, respectivamente).

A nota atribuída ao relacionamento pessoal mostrou correlação positiva estatisticamente significativa forte apenas com o outcloseness pessoal $(S=0,612, p=0,000)$, indicando a existência de uma relação linear entre as notas e a atribuição de relacionamento informal pelos alunos. A nota atribuída ao relacionamento profissional mostrou correlação positiva estatisticamente significativa moderada com tanto o incloseness quanto o outcloseness profissional $(S=0,421, p=0,003$ e $S=0,437, p=0,002$, respectivamente).

Tabela 7 - Closeness das redes informal e formal - Turma 2 (Ciências Contábeis)

\begin{tabular}{|c|c|c|c|}
\hline \multicolumn{4}{|c|}{ Informal } \\
\hline Atores & Incloseness & Atores & Outcloseness \\
\hline $\begin{array}{l}2,4,6,7,11,12,15,19,21,22,30 \\
31,32,35,37,39,40,45,46,47\end{array}$ & $\begin{array}{l}20 \text { atores } \\
\text { (Faixa } 14- \\
15,9 \%)\end{array}$ & $3,23,24,48$ & $\begin{array}{l}4 \text { atores (Faixa 1- } \\
3 \% \text { ) }\end{array}$ \\
\hline $\begin{array}{l}1,5,8,9,10,13,14,16,17,18,20 \\
23,25,26,27,28,29,33,34,36 \\
38,41,42,43,44,48\end{array}$ & $\begin{array}{l}26 \text { atores } \\
\text { (Faixa } 16- \\
18 \%)\end{array}$ & $\begin{array}{l}4,7,15,19,28,30,33,34,35 \\
37,39,40,45,47\end{array}$ & $\begin{array}{l}14 \text { atores } \\
\text { (Faixa } 22-40 \% \text { ) }\end{array}$ \\
\hline \multirow[t]{2}{*}{3,24} & $\begin{array}{l}2 \text { atores (Faixa } \\
19-20 \%)\end{array}$ & $\begin{array}{l}1,2,5,6,8,9,10,11,12,13,16, \\
18,10,21,22,26,27,29,31,32, \\
36,38,41,42,43,44,46\end{array}$ & $\begin{array}{l}27 \text { atores } \\
\text { (Faixa } 41-60 \% \text { ) }\end{array}$ \\
\hline & & $14,17,25$ & 3 atores $(61-63 \%)$ \\
\hline \multicolumn{4}{|c|}{ Formal } \\
\hline Atores & Incloseness & Atores & Outcloseness \\
\hline $\begin{array}{l}11,19,21,30,31,33,34,35,37 \\
39,40,46,48\end{array}$ & $\begin{array}{l}13 \text { atores } \\
\text { (Faixa } 25- \\
30 \% \text { ) }\end{array}$ & 23 & 1 ator (Faixa 1-3\%) \\
\hline $\begin{array}{l}2,3,4,5,6,7,8,10,12,15,16,17 \\
18,22,23,26,27,28,32,36,41 \\
42,43,44,45,47\end{array}$ & $\begin{array}{l}26 \text { atores } \\
\text { (Faixa } 30,1- \\
35 \% \text { ) }\end{array}$ & $\begin{array}{l}3,4,15,21,24,33,35,38, \\
42,47\end{array}$ & $\begin{array}{l}10 \text { atores (Faixa } 29- \\
40 \% \text { ) }\end{array}$ \\
\hline \multirow[t]{2}{*}{$1,9,13,14,20,24,25,29,38$} & $\begin{array}{l}9 \text { atores (Faixa } \\
35,1-38 \%)\end{array}$ & $\begin{array}{l}5,6,7,8,9,11,12,16,19, \\
25,26,30,31,32,34,36,37, \\
39,41,45,48 \\
1,2,10,13,17,18,20,22, \\
27,28,29,43,46\end{array}$ & $\begin{array}{l}21 \text { atores } \\
\text { (Faixa } 40,1-50 \%) \\
13 \text { atores } \\
\text { (Faixa } 51-60 \% \text { ) }\end{array}$ \\
\hline & & $14,40,44$ & $\begin{array}{l}3 \text { atores (Faixa 61- } \\
71 \% \text { ) }\end{array}$ \\
\hline
\end{tabular}




\subsection{DENSIDADE (DENSITY) E RECIPROCIDADE (RECIPROCITY)}

As redes apresentaram baixa densidade, isto é, poucas ligações entre os alunos. Por exemplo a rede informal da turma de Administração foi $12,32 \%$ de um total de 2970 ligações possíveis e a rede formal $12,49 \%$ do mesmo total. A turma de Contabilidade apresentou $16,45 \%$ e $19,77 \%$ de um total de 2256 ligações possíveis. Os resultados fornecem indícios de que a rede formal parece ser ligeiramente mais densa do que a rede informal, porém, ambas as redes apresentam grande potencial para crescer e assim haveria mais relacionamentos entre os alunos.

Com relação à reciprocidade, observou-se que os estudantes da Turma 1, tanto do gênero masculino como do feminino, possuem um percentual de relacionamento mútuo informal menor do que o percentual de relacionamento mútuo formal. De fato, o percentual de relações bidirecionais recíprocas informais entre os estudantes do gênero masculino é de $38,71 \%$, enquanto que o de formais é de $44,57 \%$. A reciprocidade indica relacionamento mais forte uma vez que ocorre nos dois sentidos. Sendo assim, o relacionamento formal apresenta maior reciprocidade, isto é, ocorre em mais pares de alunos. Entre os estudantes do gênero feminino, esses percentuais são, respectivamente, $56,45 \%$ e $60,08 \%$. Pôde-se observar, ainda, que os estudantes do gênero feminino possuem maior relacionamento mútuo do que os do gênero masculino, tanto nas relações bidirecionais informais como nas formais. Quando são consideradas as medidas gerais de relacionamento mútuo, as reciprocidades são diferentes entre as redes informal $(40,77 \%)$ e formal $(43,24 \%)$, ou seja, maior reciprocidade na rede formal (Tabela 8).

Na Turma 2, no que diz respeito ao relacionamento mútuo dos estudantes do gênero masculino, o percentual de reciprocidade na rede informal é maior do que na rede formal, ou seja, $45,16 \%$ contra $42,91 \%$, respectivamente. Contudo, essa situação se inverte quando se trata das relações bidirecionais dos estudantes do gênero feminino. Neste caso, o percentual do informal é menor do que o do formal, 66,36\% contra $67,87 \%$, isto é, as alunas do curso de contabilidade apresentam relacionamento mais forte na rede formal do que na informal. Observouse, na turma anterior que os estudantes do gênero feminino também possuem maior relacionamento mútuo do que os do gênero masculino, tanto nos relacionamentos informais quanto nos formais. Com relação às medidas gerais de reciprocidade, a Turma 2 também apresenta percentuais diferentes: $48,40 \%$ para a rede informal e $46,71 \%$ para a rede formal, porém, diferentemente da outra turma, esta mostrou maior relacionamento mútuo na rede informal. Os dados indicam, também, que a Turma 2 possui maior reciprocidade que a Turma $1 \mathrm{em}$ ambas a redes (Tabela 8). 
Tabela 8 - Reciprocidade das redes informal e formal - Turma 1 e Turma 2

\begin{tabular}{l|c|c|c|c}
\hline \multicolumn{2}{c}{ Turma 1 } & \multicolumn{2}{c}{ Turma 2 } \\
\hline \multirow{4}{*}{ Masculino } & Informal & Formal & Informal & Formal \\
\cline { 2 - 5 } & & & & \\
Feminino & $38,71 \%$ & $44,57 \%$ & $45,16 \%$ & $42,91 \%$ \\
Geral & $56,45 \%$ & $60,08 \%$ & $66,36 \%$ & $67,87 \%$ \\
\hline
\end{tabular}

Fonte: Elaborada pelos autores

Nesse sentido, constata-se que a comparação das medidas de reciprocidade formal e informal difere em relação aos cursos de administração e contabilidade e a reciprocidade formal é maior que a informal nas duas turmas. A exceção ocorre para as densidades da rede formal do gênero masculino.

\section{CONCLUSÃO}

O trabalho teve como objetivo analisar e comparar as redes sociais de amizade pessoal (informal) e de colaboração profissional (formal) de alunos universitários, segundo suas percepções e de acordo com a importância do relacionamento que eles conferem a si mesmos. Com isso, foi possível compreender as estruturas gerais das redes das duas turmas analisadas e das estruturas formal e informal, identificando as similaridades e diferenças em relação às medidas adotadas.

As notas atribuídas pelos alunos para o seu próprio grau de relacionamento com os demais colegas apresentaram notas médias próximas umas das outras para as redes informal e formal e para ambas as turmas analisadas, tanto separadamente, por gênero, quanto no geral. Esses resultados indicam similaridade entre as redes no quesito avaliação do próprio relacionamento do aluno, corroborado pelos testes de existência da correlação entre as notas dadas (informal e formal em cada turma).

Com relação às medidas de centralidade (degree), o número máximo de ligações indegree foi inferior ao de ligações outdegree nas duas turmas indicando que o aluno afirma que se relaciona com os colegas, porém, o inverso não ocorre na mesma intensidade. Apesar dessa constatação as quantidades médias de ligações por aluno não diferem de modo significativo, exceção para a turma da Contabilidade $(7,73$ para a rede informal versus 9,3 para a rede formal). Pode-se concluir que o aluno considera ter relacionamento com mais colegas do que os colegas consideram ter relacionamento com ele. Outra constatação é que as redes formais apresentam valores máximos de outdegree maiores do que as redes informais, o que indica que os alunos procuram por mais relacionamentos quando se trata de estudar juntos e de trocar informações profissionais.

A análise das medidas de centralidade Betweenness, que trata de quem tem poder nas redes, indicou valores pequenos tanto entre as turmas como entre as redes formais e informais, 
exceção ao aluno 34 da turma de Administração. Isto significa que existe pouca intermediação nas turmas e nas redes e o teste de médias indicou que a rede formal apresenta média superior à rede informal na Turma 1, o que não ocorreu na Turma 2, indicando, assim, indícios de que a intermediação é diferente entre as duas redes.

As medidas de centralidade incloseness foram consideradas baixas tanto na rede informal quanto na formal para ambas as turmas. A medida outcloseness apresentou medidas similares na turma 1 e medidas maiores na Turma 2, significando que o aluno de Contabilidade apresenta maior aproximação dos demais, porém não se pode considerar que haja diferenças significativas. Em ambas as redes o teste de Wilcoxon indica diferenças entre as médias indegree e outdgree em ambas as turmas e pode se concluir que o aluno está mais próximo dos outros no relacionamento e os outros não consideram dessa forma, em relação ao mesmo aluno.

As densidades das redes foram consideradas baixas e sem diferenças entre as mesmas e a conclusão é a de que há um potencial para que as mesmas se tornem maiores, havendo mais relacionamentos tanto formais quanto informais. Com relação à medida de reciprocidade, ocorre maior valor nas redes formais do que nas informais. Os homens apresentam o mesmo resultado na turma de Administração e resultado inverso na Contabilidade. Com relação ao gênero feminino, tanto na Administração quanto na Contabilidade, a reciprocidade é maior na rede formal do que na informal.

Os resultados apresentam uma maior centralidade na rede formal, isto é, os alunos se relacionam mais do que na rede informal quando tratam de realizar tarefas e trabalho relacionados ao curso. O mesmo ocorre com as medidas de reciprocidade das duas redes. Dessa forma este trabalho aponta algumas diferenças entres as redes formal e informal. Existem também algumas similaridades entre as redes. O fato de se trabalhar e estudar em conjunto implica em maior relacionamento do que o fato de se falar de assuntos pessoais. Há a necessidade de se replicar este trabalho em outras turmas e universidades para se confirmar as considerações aqui apresentadas.

Como consequência, ressalta-se a pluralidade dos resultados encontrados, ora semelhantes ora divergentes, tanto em relação às redes informais e formais, quanto referente às turmas analisadas. Com isso, pôde-se constatar que as redes não se superpõem umas às outras, mas sim se complementam. Sendo assim, novos estudos são sugeridos, no sentido da afirmação de Soda e Zaheer (2012), de que deve haver uma continuidade de estudos a respeito das características dos atores e das estruturas das redes. Para trabalhos futuros outras medidas da análise de redes sociais podem ser utilizadas. Por exemplo, as medidas a) structural equivalence para se analisar as conexões diretas de um ator para os outros na rede, b) cohesion e c) centralization and core-periphery índices. 


\section{REFERÊNCIAS}

AZEVEDO, T. B.; RODRIGUEZ, M. V. R. Y. Softwares para análise de redes sociais-ARS. In: CONGRESSO NACIONAL DE EXCELÊNCIA EM GESTÃO, 4., Niterói, 2010. Anais [...]. 2010.

BASTOS, V. B.; SANTOS, M. V. Redes sociais informais e compartilhamento de significados sobre mudança organizacional. Revista de Administração de Empresas, v. 47, n. 3, p. 1-13, 2007.

BORGATTI, S.P. NetDraw Software for Network Visualization. Analytic Technologies. Lexington, KY, 2002.

BORGATTI, S.P.; EVERETT, M.G.; FREEMAN, L.C. Ucinet for Windows: Software for Social Network Analysis. Harvard, MA: Analytic Technologies, 2002.

BRANDES, U.; KENIS, P.; RAAB, J. La explicación a través de la visualización de redes. REDES: Revista Hispana para el análisis de redes sociales, Universidad de Konstanz (Alemania), Universidad de Tilburg (Holanda), v. 9, n. 3, 2005. Disponível em: <https://revistes.uab.cat/ redes/article/view/v9-n2-brandes-kenis-raab>. Acesso em: 14 nov. 2016.

DAVIS, C.; SILVA, M. A. S. S.; ESPOSITO, Y. Papel e Valor das Interações Sociais em Sala de Aula. Cadernos de Pesquisa da Fundação Carlos Chagas, São Paulo, v. 71, p. 49-54, 1989.
GIGLIO, E. M.; RYNGELBLUM, A. L. Uma investigação sobre o ator consumidor na rede de pirataria e uma proposta de alternativa de estratégia de combate. Revista de Administração Mackenzie, v. 10, n. 4, p. 131-155, 2009.

GRANOVETTER, M. S. The strength of weak ties. American Journal of Sociology, v. 78, n. 6, p. 1360-1380, 1973.

HANNEMAN, R. A.; RIDDLE, M. Introduction to social network methods. Riverside, CA: University of California, Riverside, 2005.

KRACKHARDT, D.; HANSON, J. Informal Networks: The company behind the chart. Harvard Business Rewiew, Boston, v. 71, n. 4, p. 104-111, 1993.

LEONARDO, S. B. et al. Relacionamentos Interpessoais Formal e Informal: Interação das Redes no Ambiente Acadêmico. Revista de Administração Contemporânea, [S.I.], v. 23, n. 3, p. 395-415, maio 2019.

LIPNAK, J.; STAMP, J. Networks, redes de conexão: pessoas conectando-se com pessoas. São Paulo: Aquarela, 1992.

MACIEL, C. O.; CAMARGO, C. Conexão Social Intraorganizacional, Suporte no Trabalho e Identificação Organizacional/Intra-organizational Social Connection, Support at Work and Organizational Identification. Revista de Administração Contemporânea, v. 19, n. 6 (3. ed.), p. 348-366, 2015. 


\section{REFERÊNCIAS}

MARTELETO, R. M. Análise de redes sociais: aplicação nos estudos de transferência da informação. Ciência da informação, v. 30, n. 1, p. 71-81, 2001.

MARTINS, L. Os dez cursos mais buscados do país. Veja online, 2016. Disponível em: http:// veja.abril.com.br/educacao/os-dez-cursossuperiores-mais-procurados-no-brasil/. Acesso em: 18 nov. 2016.

McEVILY, B.; SODA， G.; TORTORIELLO, M. More formally: Rediscovering the missing link between formal organization and informal social structure. The Academy of Management Annals, v. 8, n. 1, p. 299-345, 2014.

MEIRELLES, C. L.; SACOMANO, J. B.; TELLES, R.; SIQUEIRA, J. P. L. Gestão de Pessoas nas Pequenas e Medias Empresas: mapeamento das redes informais, internas nas organizações, como ferramenta de recursos humanos. Revista Espacios, v. 35, n. 5, p. 16, 2014.

PASCOTTO, S. M. P.; FARINA, M. C.; RODRIGUES, T. H. P. T.; DUGO, J. C. D. Análise de rede social para mensuração das estruturas formais e informais. Revista de Administração da UFSM, v. 6, p. 179-194, 2013.

PETTERSON, A. R.; CASTRO, M. Estruturas de Redes de Cooperação Interorganizacional: O caso da Feira do Produtor. Revista Espacios, v. 37, n. 20, 2016.
RÉGIS, H. P.; BASTOS, A. V. B.; DIAS, S. M. Redes sociais informais: análise das redes de amizade, de informação e de confiança em incubadoras de base tecnológica no Recife. Revista Psicologia Organizações e Trabalho, v. 7, n.1, p. 31-56, 2007.

SILVA, A. F.; COSTA, V. M. F.; ZAMBERLAN, C. O.; COSTA, V. F. C. Análise de Redes Sociais Informais - Ferramenta para o Compartilhamento do Conhecimento Organizacional. XXXV ENANPAD, 2011.

SODA, G.; ZAHEER, A. A network perspective on organizational architecture: performance effects of the interplay of formal and informal organization. Strategic Management Journal, v. 33, n. 6, p. 751-771, 2012.

TEIXEIRA, M. R. F. Redes de conhecimento em ciências e o compartilhamento do conhecimento. Tese de doutorado, Universidade Federal do Rio Grande do Sul, RS, 2011.

WASSERMAN, S.; FAUST, K. Social Network Analysis: Methods and Applications. Cambridge University Press. New York, 1994.

\section{Taís Pasquotto Andreoli ${ }^{1}$}

Doutora pelo Programa de Pós-graduação em Administração - Universidade Municipal de Sao Caetano do Sul - USCS, São Caetano do Sul - SP, Mestre em Administração - com linha de pesquisa em Marketing - pela Universidade de São Paulo 


\section{AUTORES}

USP- São Paulo - SP. Professora e coordenadora do curso de Administração na Faculdade Anhanguera de Votorantim - São Paulo, Brasil. E-mail: tais_pa@hotmail.com

\section{Sandra Bergamini Leonardo²}

Doutoranda pelo Programa de Pós-graduação em Administração - Universidade Municipal de Sao Caetano do Sul- USCS - São Caetano do Sul - SP, Mestrado em Engenharia de Processos Químicos e Bioquímicos no Centro Universitário do Instituto Mauá de Tecnologia, São Caetano do Sul - SP, Brasil. Professora do Centro Universitário do Instituto Mauá de Tecnologia. - São Caetano do Sul - SP - Brasil. E-mail: sandraleonardo@uol.com.br

\section{Milton Carlos Farin ${ }^{3}$}

Doutorado em Administração - Faculdade de Economia, Administração e Contabilidade da Universidade de São Paulo - FEA-USP, São Paulo - SP - Brasil. Mestrado em Administração de Empresas pela Fundação Getulio Vargas - São Paulo- SP - Brasil. Professor Doutor do Programa de Pós-graduação em Administração - Universidade Municipal de Sao Caetano do Sul - USCS- São Caetano do Sul - SP. E-mail: Milton.farina@prof.uscs.edu.br

\section{Ana Boteon de Lima ${ }^{4}$}

Mestre pelo Programa de Pós-graduação em Administração - Universidade Municipal de Sao Caetano do Sul -USCS- - São Caetano do Sul - SP. Faris Assessoria Aduaneira Ltda., São
Bernardo do Campo, SP - Brasil Sócia. Atua como professora na área de comércio externior. E-mail: ana.boteon@uol.com

Data de recebimento: 04-12-2018 Data de aceite: 17-05-2018 